\title{
Specific detection of OCT4 isoforms in inflammatory bowel disease
}

\author{
Maria Maragkoudaki ${ }^{1}$, Anna Vaiopoulou ${ }^{2}$, George E. Theodoropoulos ${ }^{3}$, Evangelia Legaki ${ }^{2}$, Leonardo A. Sechi ${ }^{4}$, \\ George Karamanolis ${ }^{5}$, George Zografos ${ }^{3}$ and Maria Gazouli ${ }^{*}$
}

\begin{abstract}
Background: Developmentally early cells are mobilized into peripheral blood in Crohn's disease (CD) patients. OCT4, is considered to be important in sustaining the pluripotency of stem cells. OCT4 splicing variants are differentially expressed in pluripotent and non-pluripotent cells. Our study aims to investigate the expression pattern of OCT4 variants and SOX-2, an essential factor implicated in self-renewal and pluripotency, in tissue and blood samples from patients with IBD.

Methods: Peripheral blood and tissue samples were collected from patients with active CD and ulcerative colitis (UC), and from healthy individuals. OCT4 expression was documented by Western blot, immunohistochemistry and by reverse transcription-real-time PCR. OCT4 isoform determination was documented using specific primers. SOX-2 expression levels were also evaluated.

Results: OCT4 protein levels were significantly higher in CD tissue samples than in CD blood samples, and in UC tissue samples. OCT4 protein was localized mainly in the cytosol. In all samples, only the OCT4 pseudogenes and the OCTAB1 variant were detected. OCTAB1 expression levels were elevated in both tissue and blood samples from CD and UC cases compared to healthy controls. In CD patients only SOX-2 mRNA levels were found slightly increased compared to healthy controls.

Conclusion: Our results suggest that OCT4 is expressed in patients with IBD. Furthermore, we found the presence of the OCT 4B1 isoform in IBD in both tissue and blood samples. Our results have shown, that developmentally early cells might be mobilized into peripheral blood as result of tissue damage, indicating a possible role of these cells in repair of injured intestinal tract.
\end{abstract}

Keywords: IBD, Crohn's disease, Ulcerative colitis, Stem cells, Mobilization

\section{Background}

Crohn's disease (CD) and ulcerative colitis (UC), known as inflammatory bowel diseases (IBDs), are chronic immuno-related inflammatory diseases of unknown aetiology. However, it has been considered that IBD pathogenesis is the outcome of an aggressive cellmediated immune reaction to commensal intestinal bacteria at a genetically predisposed host [1]. Mounting evidence has been indicating that IBD pathogenesis

\footnotetext{
*Correspondence: mgazouli@med.uoa.gr

${ }^{2}$ Laboratory of Biology, Department of Basic Medical Sciences, School of Medicine, University of Athens, Michalakopoulou 176, 11527 Athens, Greece

Full list of author information is available at the end of the article
}

may be influenced by the variety of cell types involved such as stem cells (SCs), including defects of their differentiation [2]. SCs contribute to tissue homeostasis, and regeneration after damage [3]. Currently, the idea of SC-based therapies has been considered as a hopeful approach for the treatment of IBD, essentially by the use of hematopoietic SCs (HSCs) and mesenchymal SCs (MSCs) [4]. It has been supported that cells expressing markers for MSCs, HSCs, fibrocytes, enthothelial progenitors were identified in peripheral blood (PB) during tissue/organ damage, inflammation, and pharmacological therapy [5, 6]. Interestingly, Marlicz et al. [7] reported that cells expressing markers for MSCs, EPCs, and Oct- $4+$ Nanog + SSEA- $4+$ CXCR4 + lin-CD-45-very 
small embryonic-like stem cells (VSELs) are mobilized into $\mathrm{PB}$ in $\mathrm{CD}$ patients, suggesting that these cells might be important in the development and regeneration of gastrointestinal epithelium in IBD [7].

Regarding OCT4, a POU-domain transcription factor is considered to be a critical factor for the pluripotency of human embryonal stem (ES) and induced pluipotency stem (IPS) cells [8]. As cells differentiate and lose pluripotency, OCT4 is not expressed. The human OCT4 gene, situated on chromosome 6, consists of five exons and can be alternatively spliced into three basic isoforms $O C T 4 A, O C T 4 B$, and $O C T 4 B 1$, and produce four proteins OCT4A, OCT4B-190, OCT4B-265, and OCT4B164. OCT4A, usually referred as OCT4, is distinctively expressed in the nucleus of ESCs and regulates the stemness of pluripotent cells [9]. Nevertheless, the occurrence of transcribed pseudogenes with high homology to the OCT4A sequence raised questions about OCT4 as a pluripotency marker, and could be a possible source of false positive results or could lead to misinterpretation of RT-PCR experiments addressing in general OCT4 expression $[10,11]$. OCT4B is principally localized in the cytoplasm and cannot maintain the self-renewal and pluripotency of ESCs [12]. The role of OCT4B is still unclear; however, Li et al. [13] have recently supported that $O C T 4 B$ functioned as a non-coding RNA, modulating OCT4A expression in an miRNA-dependent manner [competing endogenous RNA (ceRNA) regulation] at the post-transcription level in tumour cell lines. The majority of the transcribed OCT4 pseudogenes have high homology to the OCT4A sequence only. Even if the protein product of $O C T 4 B 1$ is still not identified, it is known that $O C T 4 B 1$ is mainly expressed in human ES and EC cells and is down regulated in accordance to their differentiation [14]. Up to now, a small number of studies on OCT4 expression distinguish the different spliced isoforms and limited information exists on the expression pattern of every isoform in different cell types.

Taken into account the complexity and variety of OCT4 spliced variants and protein isoforms, the present study aimed to investigate the expression pattern of OCT4 isoforms in tissue and blood samples from patients with IBD.

\section{Methods}

\section{Subjects}

Fresh frozen tissue and blood samples from consecutive IBD patients and healthy controls were collected at the Colorectal and Inflammatory Bowel Diseases Unit, First Department of Propaedeutic Surgery of Athens Medical School, Athens, Greece. The diagnosis of IBD was based on criteria (clinical, endoscopic, radiological and pathological) [15]. The histological and immunohistochemical evaluations were done by a "blinded" observer, a pathologist who was unware of the study groups. We examined colon biopsies and blood samples from 12 patients ( 7 females, 5 males, mean age $45.6 \pm 14.5$ years) with $C D$, and from 10 patients ( 6 females and 4 males, mean age $42.5 \pm 14.5$ years) with UC. The healthy tissue and blood cohort consisted of 15 volunteers (8 females and 7 males, mean age $51.6 \pm 13$ years), they underwent standard screening colonoscopy examination and they do not have history of inflammatory, autoimmune and cancer diseases. The study was carried out with ethics committee approval, and all patients and healthy individuals gave written consent.

\section{RNA extraction and cDNA synthesis}

Total RNA was extracted from the tissue and blood specimens using the Trizol reagent (Life Technologies, Grand Island, NY, USA) according to the manufacturer's instructions. Reverse transcription was performed by incubating $1 \mathrm{mg}$ of total RNA for $1 \mathrm{~h}$ at $42{ }^{\circ} \mathrm{C}$ in the presence of $500 \mathrm{mg} / \mathrm{ml}$ of Oligo dT $12-18,10 \mathrm{mM}$ deoxyribonucleotide triphosphates, $5 \times$ first-strand buffer, $0.1 \mathrm{M}$ dithiothreitol, and $200 \mathrm{U} / \mathrm{ml}$ MMLV reverse transcriptase (Invitrogen, Carlsbad, CA, USA). Prior to RT-PCR analysis, all of the RNA samples used had been DNase-treated to reduce the risk of DNA contamination. Quantitative Real-Time Reverse Transcription PCR analysis (RealTime RT-PCR) for OCT4 gene expression and for OCT4 isoform identification was performed as previously described [10].

\section{Western blot analysis}

Frozen tissues were thawed and disrupted with a tissue lyser in RIPA buffer. Total proteins were quantified by the Lowry method. The same procedure was followed for the blood samples also. Equal concentration of proteins was loaded into an 8-12 \% SDS-polyacrylamide gel and then electrotransferred. The membranes after blocking were incubated for $16-20 \mathrm{~h}$ at $4{ }^{\circ} \mathrm{C}$ with the equivalent primary antibody. The detection of the immune complexes after incubation with the appropriate peroxidase-conjugated secondary antibody was performed with the SuperSignal West Pico Chemiluminescent substrate (Pierce). Protein expression of the molecules was expressed as relative intensity, normalized to b-actin. The primary antibodies used in the current study were: rabbit anti-OCT4 (1:1000, Proteintech, 11263-1-AP), rabbit anti-SOX2 (1:1000, Cell Signalling Technology, 2748) and rabbit anti-beta actin (1:1000, Rockland antibodies \& assays, 600-401-886), and the secondary antibody: anti-rabbit HRP (1:1000, Lifespan Biosciences, LS-C56309).

\section{Immunohistochemical analysis}

Formalin-fixed paraffin-embedded (FFPE) tissue sections were deparaffinized in xylene (Carlo-Erba Reagents, 
Milano, Italy) and rehydrated in graded alcohol. Endogenous peroxidase was deactivated by incubation with a solution of $3 \% \mathrm{H}_{2} \mathrm{O}_{2}$ (Sigma-Aldrich, St. Louis, MO, USA) in methanol (AppliChem GmbH, Darmstadt, Germany) for $10 \mathrm{~min}$. Six microwave heating cycles $(700 \mathrm{~W}$, $4 \mathrm{~min} / \mathrm{cycle}$ ) with $0.01 \mathrm{M}$ citrate buffer ( $\mathrm{pH}$ 6.0) were used for antigen retrieval. Power Block reagent (Biogenex, USA) was used for 10 min to block non-specific protein binding. Sections were subsequently incubated with rabbit anti-OCT4 (1:100, Proteintech, 11263-1-AP) primary antibody. The sections were then incubated with One-Step Polymer HRP Reagent (Biogenex, USA) secondary antibody for $30 \mathrm{~min}$. Sections were developed for 1 min in DAB (Biogenex, USA), counterstained in Gill's hematoxylin (Sigma-Aldrich), subsequently dehydrated, mounted and studied by light microscopy using a Leica CTR MIC microscope.

\section{Statistical analysis}

The statistical analyses were done using GraphPad v. 3.00 (GraphPad Software, San Diego, CA, USA). Experiments were performed in triplicates. Positivity rates and differences in expression among the groups were calculated using the Chi square test and the non-parametric
Wilcoxon rank sum test, respectively. Probability values of $<0.05$ were considered significant.

\section{Results}

We first analysed the expression of OCT4 protein levels in blood and tissue samples from CD and UC patients. As indicated in Fig. 1, OCT4 was expressed in both tissue and blood samples from $\mathrm{CD}$ and UC cases. OCT4 protein levels were significantly higher in $\mathrm{CD}$ tissue samples compared to CD blood samples $(\mathrm{p}<0.05)$ and to UC tissue samples $(\mathrm{p}<0.01)$. We also examined the expression of the ESC marker SOX-2 with the aim of determine if the OCT4 expression pattern related to a stem cell phenotype also. Similarly SOX-2 was significantly higher in CD tissue samples compared to CD blood samples $(\mathrm{p}<0.05)$ and to UC tissue samples $(\mathrm{p}<0.05)$. Interestingly, as indicated in Fig. 2 OCT4 protein was expressed mainly in the cytosol in both CD and UC cases, which is different from the description about OCT4 as a nuclear protein. It is known that the different OCT4 isoforms can be distinguished by their different subcellular localization.

In order to reliably discriminate isoforms OCT4A from $O C T 4 B, O C T 4 B 1$ and all the known pseudogenes we used the RT-PCR method followed by restriction

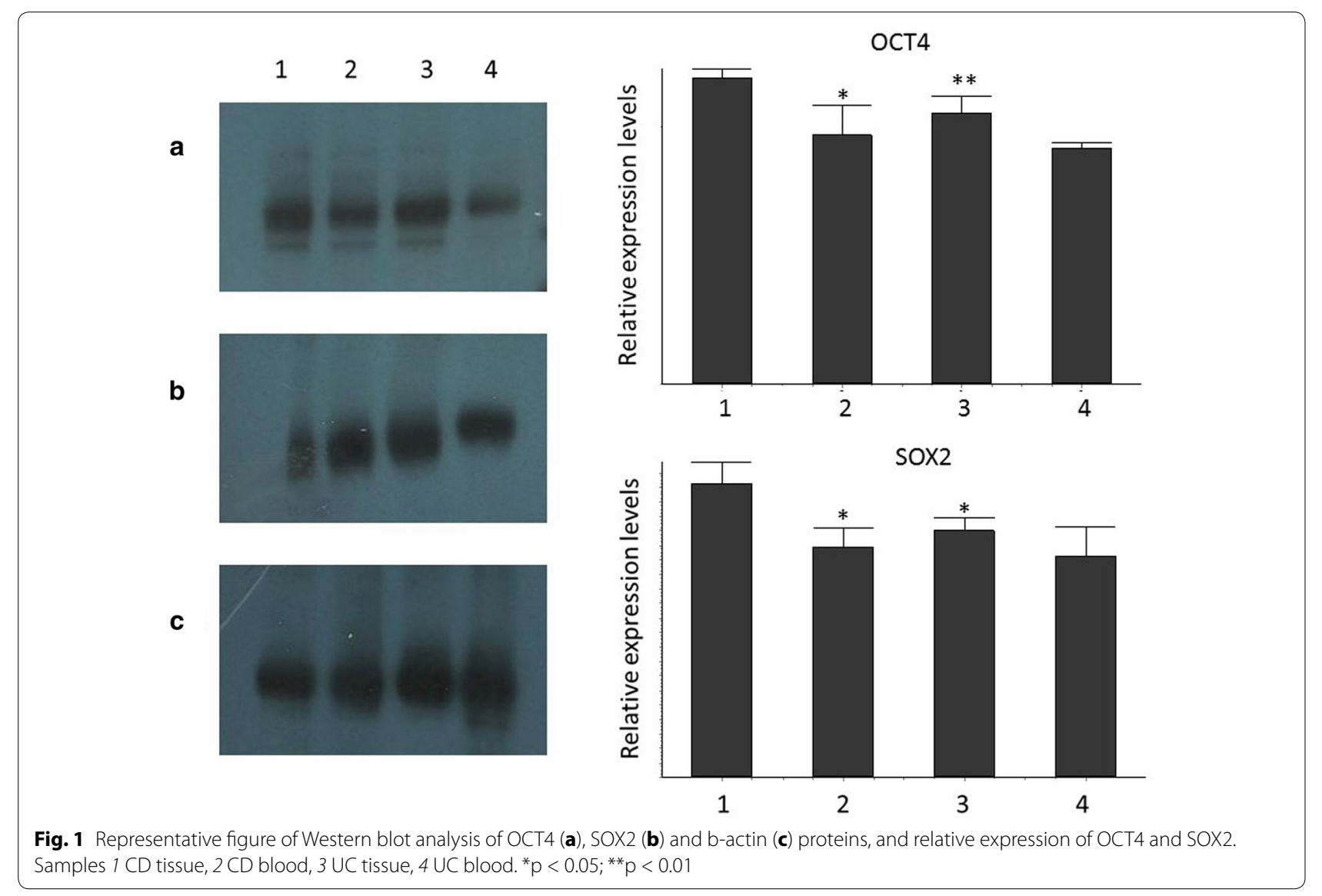



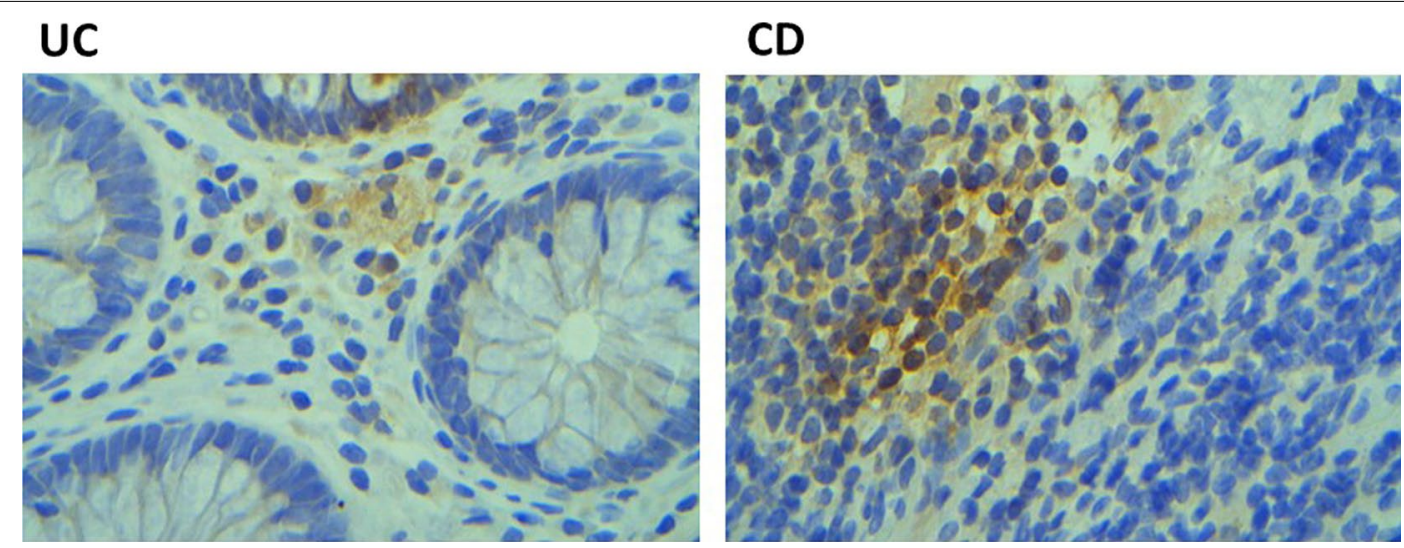

Fig. 2 Representative immunohistochemical OCT4 expression analysis of CD and UC tissues

fragment analysis and OCT4B1 specific primers as previously described $[10,14,16]$. As indicated in Fig. 3 in all cases only the OCT4 pseudogenes and the $O C T 4 B 1$ variant were detected. The expression pattern of OCT4B1 variant in $\mathrm{CD}, \mathrm{UC}$ and healthy tissues and blood samples was further examined. As indicated in Fig. 4, OCT4B1 expression levels were elevated in both tissue and blood samples from CD and UC cases compared to healthy controls. Particularly, in blood samples OCTAB1 was expressed $6.95 \pm 1.59$-fold greater in $\mathrm{CD}$ and $3.55 \pm 0.57$-fold greater in UC compared with healthy controls. Similar results were obtained in tissues samples, also $(5.45 \pm 1.12$-fold greater in $\mathrm{CD}$ and $2.74 \pm 0.53$-fold greater in $\mathrm{UC}$, respectively). The OCT4B1 mRNA levels were higher in blood samples compared to tissue samples from $C D$ patients. The samples from $C D$ patients expressed higher levels of OCT4B1 mRNA compared to respective samples from the UC patients. The mRNA levels of $S O X-2$ were found slightly increased compared to healthy controls, in both

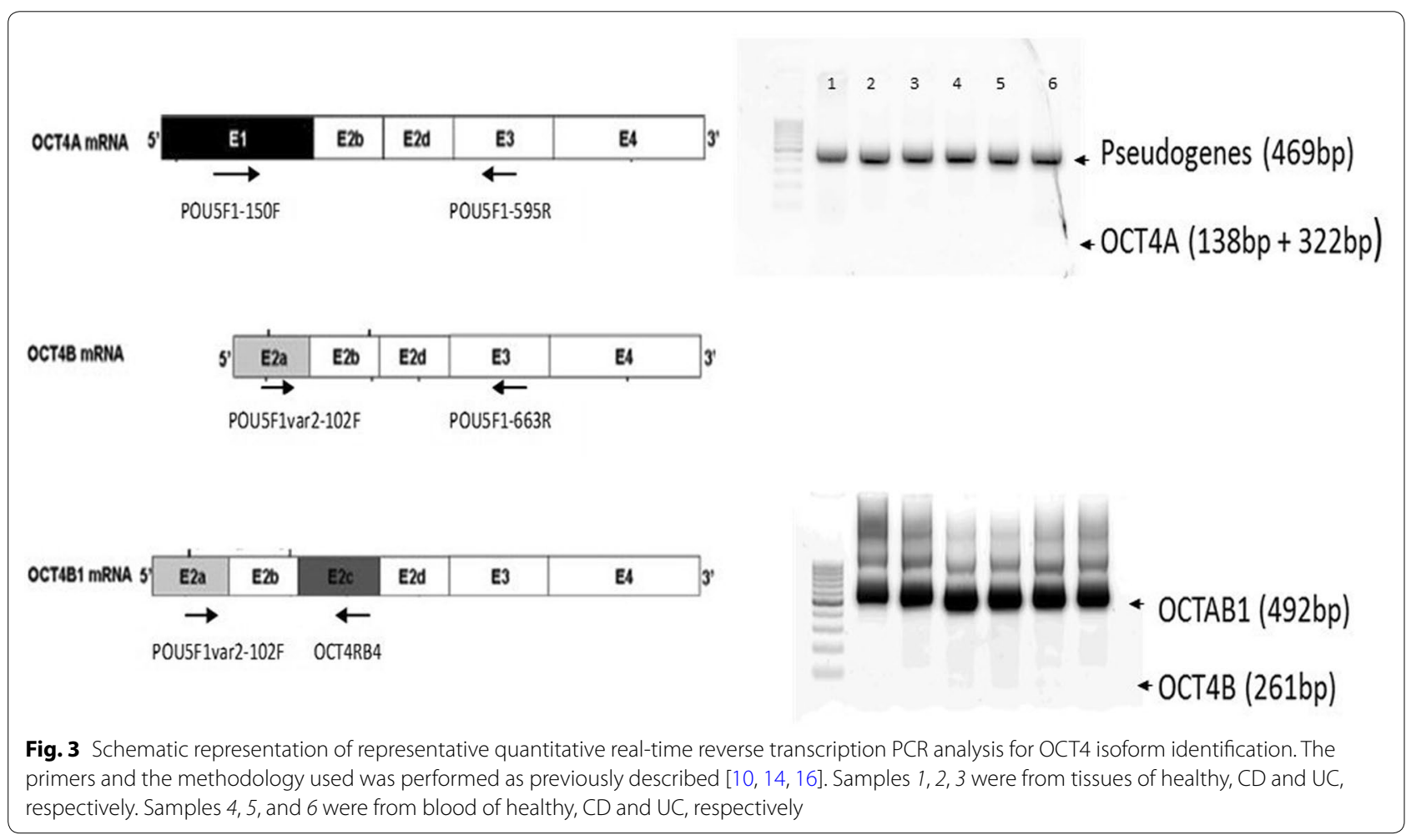




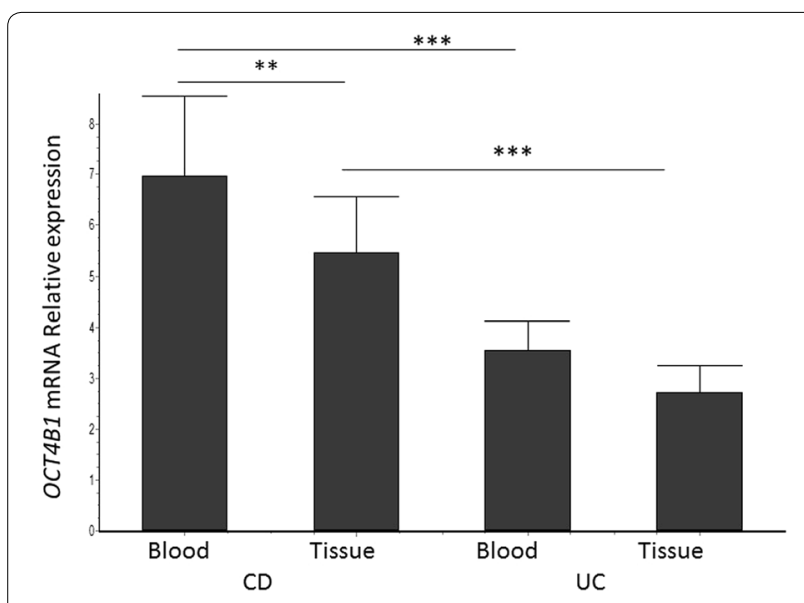

Fig. 4 Fold increase of OCTAB1 mRNA from CD, UC compared to healthy tissue and blood samples. Relative expression level was measured by quantitative real-time RT-PCR

blood $(0.91 \pm 0.17$-fold $)$ and tissue samples $(0.84 \pm 0.14$ fold) of CD patients only.

\section{Discussion}

In our study, Western blot analysis of CD and UC tissues and blood samples showed the expression of OCT4 and SOX-2. Thus, in agreement with recent data from Marlicz et al., our findings indicate that stem-like cells might exist in the tissue and blood samples from $C D$ and UC patients [7]. Even if, the expression of OCT4 has been reported mostly in human cancers and cancer cell lines, its expression in IBD has not been systematically investigated. In the present study, IHC analysis of $\mathrm{CD}$ and UC tissues showed that positive OCT4 staining was mainly found in the cytoplasm, which is different from the description that OCT4 is a nuclear protein. Since it is known that OCT4 isoforms can be distinguished by their specific subcellular localization [17], in order to characterize OCT4 isoform and all its presently known pseudogenes, we used RT-PCR/restriction digestion analysis, as previously described $[10,16]$. Our findings suggest that $O C T 4 A$ and $O C T 4 B$ isoforms are not expressed in our IBD cases however the presence of the OCT4 pseudogenes was found instead. It has been suggested that the transcription of pseudogenes could regulate OCT4 gene activity [18]. It is interesting to notice that the novel OCT4 variant nominated as OCT4B1 was universally expressed in IBD. Atlasi et al. [14] suggested that while ESCs/ECs are expressed at very low levels the novel $O C T 4 B$ isoform, i.e. the OCT4B1 variant is greatly expressed in these cells [7]. Consequently, our findings support a possible association between OCT4B1 expression and the presence of a pluripotent/undifferentiated state of stem cell-like cells in IBD cases, and support that the expression of OCT4 observed in the IBD cases is due to the expression of the OCT4B1 isoform. OCT4B1 endows an anti-apoptotic property, especially under stress conditions [19-21]. The inhibition of apoptosis in an important regulatory pathway implicated in the gut immune system and IBD pathogenesis [22]. However, the mechanism by which OCT4B1 regulates the apoptotic pathway is not yet clarified. The mRNA levels of the OCT4B1 were found to be higher in blood samples compared to tissue samples of both CD and UC cases.

It is known that stem cells are mainly derived from bone marrow, and are circulating continuously at a low level in peripheral blood. Hematopoietic and non-hematopoietic stem cells can be mobilized into peripheral blood. These cells are mobilized and circulate during tissue/ organ injuries. It has been suggested that mobilized cells have a potential role in brain regeneration after stroke, skin burn injury, and acute myocardial infarction [23]. Mobilized stem cells have multiple functions. They contribute to tissue regeneration and to inflammation control by secreting several cytokines that suppress the local immune response [24-26]. In intestine, tissue regeneration may be contributed by stem cells residing in intestinal crypts. Moreover, the immune response suppressing role of these cells makes them a potential therapeutic target for inflammatory diseases such as IBD which is a disease with abnormal mucosal immune response. However, various causes may influence the number of circulating stem cells, such as local inflammation, strenuous exercise, tissue damage and pharmacological factors [6]. It is lately reported that immunosuppressants such as azathioprine, affect stem cell migratory behaviour and influence their therapeutic ability [27].

\section{Conclusion}

In conclusion, our findings show that the presence of stem cells in peripheral blood is expected. Furthermore, we found the presence of the OCT4B1 isoform in IBD in both tissue and blood samples. Our results have shown that patients with tissue/organ injury and inflammation are likely to modulate a big number of stem cells form bone marrow, which probably either move in the intestine and contribute to regeneration or remain in circulation and regulate immune response.

\section{Authors' contributions}

MG, GET, GK participated in the design of the study. MG, AV wrote the manuscript. MM, AV, EL collected the samples and performed the experiments. GZ, LAS revised the manuscript critically and interpreted the data. All authors read and approved the final manuscript.

\section{Author details}

${ }^{1}$ First Department of Pediatrics, Athens University Medical School, "Aghia Sophia" Children's Hospital, Athens, Greece. ${ }^{2}$ Laboratory of Biology, Department of Basic Medical Sciences, School of Medicine, University of Athens, Michalakopoulou 176, 11527 Athens, Greece. ${ }^{3}$ Colorectal and Inflammatory 
Bowel Diseases Unit, First Department of Propaedeutic Surgery of Athens Medical School, Athens, Greece. ${ }^{4}$ Sezione di Microbiologia e Virologia, Dipartimento di Scienze Biomediche, Università degli Studi di Sassari, Sassari, Italy.

${ }^{5}$ Department of Surgery, "Aretaieio" University Hospital, Athens, Greece.

\section{Compliance with ethical guidelines}

\section{Competing interests}

The authors declare that they have no competing interests.

Received: 30 July 2015 Accepted: 23 September 2015

Published online: 01 October 2015

\section{References}

1. Lapaquette P, Brest P, Hofman P, Darfeuille-Michaud A. Etiology of Crohn's disease: many roads lead to autophagy. J Mol Med. 2012;90(9):987-96.

2. Gersemann M, Stange EF, Wehkamp J. From intestinal stem cells to inflammatory bowel diseases. World J Gastroenterol WJG. 2011;17(27):3198-203

3. Moossavi S, Zhang H, Sun J, Rezaei N. Host-microbiota interaction and intestinal stem cells in chronic inflammation and colorectal cancer. Expert Rev Clin Immunol. 2013;9(5):409-22.

4. Gazouli M, Roubelakis MG, Theodoropoulos GE. Stem cells as potential targeted therapy for inflammatory bowel disease. Inflamm Bowel Dis. 2014;20(5):952-5.

5. Kucia MJ, Wysoczynski M, Wu W, Zuba-Surma EK, Ratajczak J, Ratajczak $M Z$. Evidence that very small embryonic-like stem cells are mobilized into peripheral blood. Stem Cells. 2008;26(8):2083-92.

6. Hess DA, Allan AL. Migratory strategies of normal and malignant stem cells. Methods Mol Biol. 2011;750:25-44.

7. Marlicz W, Zuba-Surma E, Kucia M, Blogowski W, Starzynska T, Ratajczak MZ. Various types of stem cells, including a population of very small embryonic-like stem cells, are mobilized into peripheral blood in patients with Crohn's disease. Inflamm Bowel Dis. 2012;18(9):1711-22.

8. Nichols J, Zevnik B, Anastassiadis K, Niwa H, Klewe-Nebenius D, Chambers I, Scholer H, Smith A. Formation of pluripotent stem cells in the mammalian embryo depends on the POU transcription factor Oct4. Cell. 1998;95(3):379-91.

9. Lee J, Kim HK, Rho JY, Han YM, Kim J. The human OCT-4 isoforms differ in their ability to confer self-renewal. J Biol Chem. 2006;281(44):33554-65.

10. Gazouli M, Roubelakis MG, Theodoropoulos GE, Papailiou J, Vaiopoulou A, Pappa KI, Nikiteas N, Anagnou NP. OCT4 spliced variant OCT4B1 is expressed in human colorectal cancer. Mol Carcinog. 2012;51(2):165-73.

11. Zangrossi S, Marabese M, Broggini M, Giordano R, D'Erasmo M, Montelatici E, Intini D, Neri A, Pesce M, Rebulla P, et al. Oct-4 expression in adult human differentiated cells challenges its role as a pure stem cell marker. Stem Cells. 2007;25(7):1675-80.

12. Cauffman G, Liebaers I, Van Steirteghem A, Van de Velde H. POU5F1 isoforms show different expression patterns in human embryonic stem cells and preimplantation embryos. Stem Cells. 2006;24(12):2685-91.
13. Li D, Yang ZK, Bu JY, Xu CY, Sun H, Tang JB, Lin P, Cheng W, Huang N, Cui RJ, et al. OCT4B modulates OCT4A expression as ceRNA in tumor cells. Oncol Rep. 2015;33(5):2622-30.

14. Atlasi Y, Mowla SJ, Ziaee SA, Gokhale PJ, Andrews PW. OCT4 spliced variants are differentially expressed in human pluripotent and nonpluripotent cells. Stem Cells. 2008;26(12):3068-74.

15. Podolsky DK. The current future understanding of inflammatory bowel disease. Best Pract Res Clin Gastroenterol. 2002;16(6):933-43.

16. Panagopoulos I, Moller E, Isaksson M, Mertens F. A PCR/restriction digestion assay for the detection of the transcript variants 1 and 2 of POU5F1. Genes Chromosom Cancer. 2008;47(6):521-9.

17. de Resende MF, Chinen LT, Vieira S, Jampietro J, da Fonseca FP, Vassallo J, Campos LC, Guimaraes GC, Soares FA, Rocha RM. Prognostication of OCT4 isoform expression in prostate cancer. Tumour Biol J Int Soc Oncodev Biol Med. 2013;34(5):2665-73.

18. Suo G, Han J, Wang X, Zhang J, Zhao Y, Zhao Y, Dai J. Oct4 pseudogenes are transcribed in cancers. Biochem Biophys Res Commun. 2005;337(4):1047-51.

19. Mirzaei MR, Najafi A, Arababadi MK, Asadi MH, Mowla SJ. Altered expression of apoptotic genes in response to OCT4B1 suppression in human tumor cell lines. Tumour Biol J Int Soc Oncodev Biol Med. 2014;35(10):9999-10009.

20. Asadzadeh J, Asadi MH, Shakhssalim N, Rafiee MR, Kalhor HR, Tavallaei M, Mowla SJ. A plausible anti-apoptotic role of up-regulated OCT4B1 in bladder tumors. Urol J. 2012;9(3):574-80.

21. Farashahi Yazd E, Rafiee MR, Soleimani M, Tavallaei M, Salmani MK, Mowla SJ. OCT4B1, a novel spliced variant of OCT4, generates a stable truncated protein with a potential role in stress response. Cancer Lett. 2011;309(2):170-5.

22. Pedersen J, LaCasse EC, Seidelin JB, Coskun M, Nielsen OH. Inhibitors of apoptosis (IAPs) regulate intestinal immunity and inflammatory bowel disease (IBD) inflammation. Trends Mol Med. 2014;20(11):652-65.

23. Wojakowski W, Tendera M, Kucia M, Zuba-Surma E, Paczkowska E, Ciosek J, Halasa M, Krol M, Kazmierski M, Buszman P, et al. Mobilization of bone marrow-derived Oct-4+ SSEA-4+ very small embryonic-like stem cells in patients with acute myocardial infarction. J Am Coll Cardiol. 2009;53(1):1-9.

24. Caplan Al, Dennis JE. Mesenchymal stem cells as trophic mediators. J Cell Biochem. 2006;98(5):1076-84.

25. Kyrkanides S, Miller AW, Miller JN, Tallents RH, Brouxhon SM, Olschowka ME, O'Banion MK, Olschowka JA. Peripheral blood mononuclear cell infiltration and neuroinflammation in the HexB-/- mouse model of neurodegeneration. J Neuroimmunol. 2008;203(1):50-7.

26. Mokbel AN, El Tookhy OS, Shamaa AA, Rashed LA, Sabry D, El Sayed AM. Homing and reparative effect of intra-articular injection of autologus mesenchymal stem cells in osteoarthritic animal model. BMC Musculoskelet Disord. 2011;12:259.

27. Schneider N, Goncalves Fda C, Pinto FO, Lopez PL, Araujo AB, Pfaffenseller B, Passos EP, Cirne-Lima EO, Meurer L, Lamers ML, et al. Dexamethasone and azathioprine promote cytoskeletal changes and affect mesenchymal stem cell migratory behavior. PloS One. 2015;10(3):e0120538.

\section{Submit your next manuscript to BioMed Central and take full advantage of:}

- Convenient online submission

- Thorough peer review

- No space constraints or color figure charges

- Immediate publication on acceptance

- Inclusion in PubMed, CAS, Scopus and Google Scholar

- Research which is freely available for redistribution 